I am indebted to Dr. Franks, Banting Institute, Toronto, for the sarcoma 37 and to Hansi Kroeker and Miss Melville and staff for technical assistance. The work was supported by a grant from the National Cancer Institute of Canada.

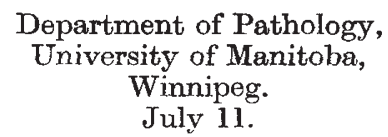

\section{A Proprioceptor in the Body Musculature of Lepidoptera}

DURING a study of muscle histolysis in saturniid moths ${ }^{1}$, sense organs were found in association with the intersegmental muscles. So far as we can ascertain, they are of a type not previously described for insects. They resemble the receptors discovered by Alexandrowicz in the Crustacea. Each receptor consists of a modified muscle fibre in which the striations are faint, but which is capable of contraction. In the final instar larva of Antheraea pernyi, there is a pair of these receptors in the meso- and meta-thorax and in abdominal segments 1-9. The receptors lie in the dorsal longitudinal muscles ${ }^{1}$ and are attached to the epidermis at the intersegmental folds. They persist during metamorphosis and are present in the abdomen of the pupa and adult, but so far they have not been located in the thorax of these stages. Near the middle of the fibre, a swelling is formed by an ovoid sac filled with an unidentified substance which stains with some nuclear stains such as hæmatoxylin and celestin blue. Attached to the receptor at this point is a single large sensory neurone the dendrites of which enter a fibre tract running the full length of the receptor. The fibre tract appears to be composed of connective tissue fibres. A rich motor innervation is present, with nerve endings at intervals all along the organ. Similar receptors have been found in Platysamia cecropia, Telea polyphemus, Samia walkeri and Actias selene.

The function of the receptors of the pupa of $A$. pernyi has been investigated oscillographically. After exposure of a single receptor with a suitable length of nerve, a strip of euticle bearing the receptor is removed from the pupa. Flaps of cuticle from the neighbouring segments are left at either end of the preparation. These flaps are clamped in an apparatus designed for stretching and relaxing the receptor. It consists of a 'Perspex' trough with a fixed clamp for one end of the cuticle strip and an adjustable clamp for the other end. The adjustable clamp is attached to a metal rod which can be locked when the preparation is in a suitable position. The bracket for the rod is in turn attached to a solenoid which causes the rod and clamp to flick to and fro in the direction of the longitudinal axis of the preparation. The amount of stretching and relaxation thus imposed on the receptor is controlled by micrometer screws. Through. out the experiments the preparation is immersed in insect Ringer's solution ${ }^{3}$.

A regular single unit impulse discharge can be recorded from this preparation. The duration of impulse is approximately 5 msec, at room temperature, and the discharge frequency depends on the tension. Frequencies of about 30 impulses/sec. are commonly found when the preparation is set up with a minimum of tension. The discharge activity continues unaltered for an hour and longer. Stretching the preparation evokes an immediate increase in the discharge frequency, and the higher level of activity is maintained while the stretch lasts. There is a certain amount of adaptation; but the time course of the adaptation is very slow. After cessation of stretch, there is a marked post-stimulatory depression followed by a gradual return of the impulse activity to the initial discharge frequency.

The presence in insects of proprioceptor organs closely resembling both in structure and in mode of function $^{4}$ those recently discovered in Crustacea appears to be of considerable interest. A detailed study of the histological structure of the organ and of the quantitative aspects of its responses is in progress, and the results will be published elsewhere.

\section{H. Findayson OTTO LOWENSTEIN}

Department of Zoology and

Comparative Physiology,

University of Birmingham,

Edgbaston, Birmingham 15. July 29.

${ }^{1}$ Finlayson, L. H. (in the press) 2 Alexandrowicz, J. S., Quart. J. Micr. Sci., 76, 511 (1984); 92, 163
(1951); 93, 315 (1952); J. Mar. Biol. Assoc. U.K., 31, 277 (1951);

${ }^{3}$ Ephrussi, B., and Beadle, G. W., Amer. Nat., 70, 218 (1936).

4 Wiersma, C. A. G., Furshpan, E., and Florey, E., J. Exp. Biol., 30, 136 (1953).

\section{Sodium Extrusion in Muscle}

THE extrusion of sodium from the living cell against a concentration gradient has been demonstrated by Steinbach $^{1}$, Desmedt ${ }^{2}$ and Maizels ${ }^{3}$. The mechanism of such an extrusion is often referred to as a 'sodium pump'. We have repeated the above experiment with nerve and muscle; but we find it difficult to obtain consistent results, because toad (Bufo marinus) tissue does not always lose potassium and gain sodium in the cold. This pump is not entirely activated by temperature change, as the above authors neglect to stress that extrusion of sodium does not take place unless the external potassium is increased above physiological level.

In the course of work on ionic equilibria ${ }^{4,5}$, we had occasion to investigate the level to which the intra. cellular sodium would fall when the tissues were placed in Ringer solution of which half the sodium had been replaced by sucrose. A pair of muscles (or nerves) is allowed to equilibrate in normal Ringer solution for $2 \mathrm{hr}$. (longer for nerves), and then one member is analysed and the companion transferred to Ringer solution in which half the sodium has been replaced by sucrose. It is found that the intra. cellular sodium decreases to half that of the control. It will be apparent from a study of Fig. 1 that this sodium has been extruded against a chemical gradient. We have found that this 'pump' is extremely reliable when contrasted with the vagaries of the Steinbach pump.

A survey of the time relationships shows that the sodium extrusion may be complete (in small muscles) in as short a period as half an hour, usually within an hour, and no further ionic alteration takes place during the following three hours.

The 'pump' described differs in one particular respect from that of Stoinbach in that the potassiumlevels remain constant thr ughnut the whole of the experiment, whereas according to Sto inbach there is a concomitant pumping in of potassium when the 